\title{
A QUESTÃO DEMOCRÁTICA NA AGENDA DA OEA NO PÓS-GUERRA FRIA
}

\author{
Rafael A. D. Villa \\ Universidade de São Paulo
}

RESUMO

O objetivo deste trabalho é examinar de que maneira a Organização dos Estados Americanos (OEA), por meio de suas Missões de Observadores (MOE-OEA), vem institucionalizando práticas de democracia representativa no sistema interamericano. A partir das eleições peruanas de 2000, o artigo mostra as limitações dos princípios democráticos quando eles confrontam-se com o princípio de não-intervenção sustentado em atuações defensivas de potências médias (caso do Brasil) e pequenos atores estatais. Organizações como a OEA vêm incorporando em sua agenda a democracia com uma intensidade pouco usual na sua história diplomática. O artigo conclui que tal explicitação democrática da OEA nem sempre se traduz em resultados bem-sucedidos. Existem constrangimentos que passam pela própria institucionalização de seus procedimentos de monitoramento, pelos interesses políticos e econômicos das potências regionais e pelo sempre espinhoso problema dos limites entre monitoramento e nãointervenção nos assuntos internos dos países membros.

PALAVRAS-CHAVES: Organização dos Estados Americanos; democracia; não-intervenção; missões de observadores.

\section{A OEA E A GLOBALIZAÇÃO DA POLÍTICA}

A reemergência de instituições intergovernamentais e não-governamentais, com papéis mais ativos na política regional e mundial, é uma característica marcante na reformulação do quadro institucional internacional do pós-Guerra Fria. Essas organizações, velhas e novas, redefinem papéis de uma forma que poderíamos chamar de alta especialização institucional da política mundial. Essa alta especialização evidentemente não representa nenhuma novidade: a novidade parece residir em que seus papéis tornaram-se mais definidos e, em alguns casos, passaram a ter um poder de coerção, bem seja de natureza diplomática, econômica ou militar. Dessa maneira poderíamos sugerir que hoje em dia, para cada área importante da política mundial, existem instituições especializadas que asseguram um mínimo de "governabilidade internacional" ou de good governance. $\mathrm{O}$ campo da segurança estratégica internacional vem sendo assumida de maneira mais atuante pelo Conselho de Segurança da Organização das Nações Unidas (ONU) e pela Organização do Tratado do Atlântico Norte (OTAN); o campo financeiro pelo Fundo Monetário Internacional (FMI) e pelo Banco Mundial (BIRD); a área comercial pela Organização
Mundial do Comércio (OMC), e a área políticodiplomática pelo chamado G-7.

Paralelamente a um crescente processo de globalização e de especialização mundial da política, opera-se também um outro, ascendente, de regionalização da política. Ele é pensado nas suas origens em termos de regionalização econômica (União Européia, NAFTA, Mercosul etc.), portanto como um processo cujo protagonista principal é o Estado, mesmo que o princípio que oriente sua ação de longo prazo possa ser, como no caso da União Européia, a possibilidade de sua transformação numa experiência supranacional, o que certamente implica o enfraquecimento do ator estatal. De outro lado, as transformações do pós-Guerra Fria permitiram também a redefinição das funções de instituições intergovernamentais políticas e de segurança mundiais e regionais. Como atenta Guimarães: "Na área política, a estratégia é definir e negociar compromissos internacionais que incorporem regras de bom governo - good governance - a serem seguidas pelos países periféricos, tais como a adoção da democracia representativa como único regime aceitável de governo; controle da corrupção; direitos humanos e de minorias; legislação social e trabalhista; política de meio ambiente 
e desarmamento nuclear e convencional. Essas normas seriam sancionadas através de organismos regionais ou de organismos multilaterais" (GUIMARÃES, 1999, p. 113-114).

O caso da Organização dos Estados Americanos (OEA) parece emblemático nesse sentido. Durante a Guerra Fria foi limitada a possibilidade de os Estados Unidos utilizarem o Conselho de Segurança da ONU como uma instância punitiva global devido à freqüente utilização do poder de veto soviético. Dessa maneira, a potência do Norte teve que reordenar sua estratégia no sentido de aproveitar melhor o espaço e as brechas deixadas pela existência de algumas organizações multilaterais regionais (de natureza diplomática e de segurança). Nessa estratégia encaixou-se bem a OEA: a organização, em várias oportunidades, agiu como instância de legitimação dos embates ideológicos, das invasões e da capacidade punitiva (militar ou econômica) desenvolvida pelos EUA contra alguns países da região, como a Guatemala de Jacobo Arbenz (1954), a Cuba de Fidel Castro (1962), a República Dominicana de Bosch (1965), a Granada de Hudson Austin (1983) e o Panamá de Noriega (1989). Em outras palavras, não constitui nenhuma novidade que organismos multilaterais regionais sejam utilizados como mecanismos de legitimação da ação estatal internacional do ator hegemônico. No período da Guerra Fria, como agir de outra maneira quando existia uma outra ideologia concorrente com pretensões de universalidade e o triunfo de qualquer uma delas significava necessariamente um jogo de soma zero?

Com a queda da União Soviética já não existe mais, hoje, tal concorrência ideológica e o que se vem chamando de globalização da política ou de governabilidade internacional coincide em muito com uma das grandes tradições e objetivos da política externa americana: a aceitação como valor e como prática de sua concepção liberal de democracia. Como argumenta Kissinger, "as peculiaridades que os Estados Unidos se atribuíram ao longo da história resultaram em duas posturas contraditórias da política externa. Primeira, a de que os EUA melhor atendem a seus valores aperfeiçoando a democracia em casa e servindo assim de farol para o resto da humanidade; segunda, a do que os valores americanos impõem aos EUA a obrigação de promovê-los no mundo inteiro" (KISSINGER, 1999,p. 14).

Uma pergunta relevante é: caberia pensar em um desmonte de organizações do tipo da OEA, dado que o concorrente ideológico dos EUA "desmanchou no ar"? Evidentemente a resposta é quase necessariamente negativa: nem os estados hegemônicos possuem uma visão tão conjuntural da política internacional e nem o triunfo da idéia democrática (para utilizar palavras caras a Fukuyama) significa que todos os estados ipso facto adotaram o modelo da democracia ocidental. Ou, melhor dito, aceita-se com facilidade a essência, o valor, porém esse valor ainda está longe de concretizarse em práticas e instituições democráticas permanentes, ao gosto dos Estados Unidos.

Não caberia então o desmonte de organizações regionais multilaterais, posto que são importantes para irem constituindo as bases da universalização democrática. E como se trata de um princípio no qual todos os atores estatais que formam parte da Organização apresentam um consenso valorativo, a tarefa parece facilitada. Coerentemente com isso, quase coincidindo com o desmoronamento soviético, a OEA aprovou em 1991 a Resolução n. 1080, ou "cláusula democrática", que prevê a suspensão da participação no sistema interamericano daqueles países onde exista quebra da ordem constitucional e institucional democrática. Dito de outra maneira, em certas circunstâncias o exercício do poder internacional não privilegia necessariamente seus aspectos físicos ou materiais porém seus aspectos valorativos, traduzidos em luta pelo exercício de hegemonia. Certamente, a definição de uma agenda internacional que inclua esse aspecto depende da correlação ou distribuição de forças internacionais. A promoção da democracia como forma global de governo não é fixa mas depende da distribuição do poder, "São as relações de força que determinam, numa larga medida, a escolha dos problemas [e dos valores] que convém atacar se se quer manter a ordem existente, neutralizando os elementos capazes de a lesar" (COX \& JACOBSON, 1990, p. 403).

Com a globalização da política, meio do valor da democracia ocidental, trata-se exatamente de "neutralizar" e de reconstruir mas não de destruir ordens políticas de países que, em princípio, são mais amigos que inimigos. Isto é, em um mundo polarizado ideologicamente, como aquele da Guerra Fria, valia a definição de Carl Schmidt de que a relação básica da política é a dicotomia amigoinimigo (SCHMIDT, 1992). Nesse campo de forças as posições intermediárias ficavam sobrando. Aliás, segundo essa perspectiva analítica, com a globalização unidimensional da política, baseada da crença no valor universal da democracia 
ocidental, um dos campos da metáfora política de Schmidt (o inimigo) tende a desaparecer. Por essa via também chegaríamos ao fim da política. Fora essa polêmica idéia, o relevante do caso é constatar que os atritos em torno do tema da democracia passam, atentando sempre à natureza pública do conceito e não a seu caráter privado, a uma luta no campo dos amigos. Ou, para utilizar uma metáfora da linguagem da guerra, os eventuais feridos desses confrontos estão sendo "atingidos pelo fogo amigo" e não pelo fogo inimigo.

Descrito esse panorama conceitual no qual se articula uma organização multilateral regional no pós-Guerra Fria, uma questão de fundo que aparece é: o que leva uma organização a exigir de um de seus membros a adequação de suas instituições, e da sua natureza, aos princípios e regras do jogo da democracia? Qual é a legitimidade desse procedimento de construção exógena de valores e de instituições? A organização ou reorganização do Estado-nação e de suas instituições e a escolha dos valores na base de que se organizam instituições historicamente é um processo endógeno, isto é, sancionado a partir da comunidade política nacional. Esse procedimento é o que confere legitimidade à ordem política de qualquer país. A soberania interna de um pais implica necessariamente que a deliberação da agenda política interna corresponda a um processo de legitimação por meio de mecanismos definidos para esse efeito pela comunidade política nacional.

Poderíamos sugerir três possíveis hipóteses para esses problemas. Primeiro, que os regimes de natureza democrática são menos alentados pelo desejo da guerra ou pelas atitudes belicosas. De acordo com as conhecidas palavras de Bobbio, regimes de natureza democrática nunca foram à guerra durante o século XX (BOBBIO, 1984). Essa hipótese parece desconhecer que, como ensinava Hobbes, a guerra nem sempre consiste no choque direto dos combatentes mas numa constante disposição para tal ação. Segundo, a própria idéia de que estamos mesmo numa era do fim das ideologias, como sustenta o refinado argumento de Francis Fukuyama. Sem concorrentes universais, a democracia liberal impõe-se como imperativo categórico, decorrente da superioridade e coerência ética de seus postulados normativos. Como o próprio Fukuyama reconheceu, o grande problema desse argumento é que ele tem que ser levado a sério sempre que pensemos o mundo em uma perspectiva racionalista e ideal, porque ainda se está muito longe de sua realização no mundo material. Para ficarmos num exemplo só, a China, que alberga $1 / 6$ da população mundial, não parece ainda muito disposta a aceitar a superioridade material da idéia de democracia. Em outras palavras, é inegável que existe uma discrepância suficientemente não resolvida entre racionalidade ideal e racionalidade material, entre a verdade efetiva das coisas e o desejo de que a realidade fosse de outra maneira.

Uma terceira hipótese, que sem dúvida é conseqüência das duas primeiras, é que as organizações internacionais contemporâneas incorporam cada vez mais a exigência de seus membros contarem com regimes de natureza democrática. Entre as cláusulas democráticas aprovadas pela OEA nos anos 1990 encontram-se o respeito ao Estado de Direito, às liberdades civis e ao pluralismo. Em outras palavras, os membros da OEA vêm sendo obrigados pela estrutura jurídica da organização a incorporarem cláusulas democráticas de compromisso e de acatamento obrigatório como um requisito sistêmico de adequação às necessidades normativas de ordenamento, equilíbrio e estabilidade da política internacional do pós-Guerra Fria. Ou seja, passam a ser vinculados e obrigados a democratizar-se a partir de uma certa racionalidade formal não de caráter nacional mas exógena, internacional.

Novamente, o problema aqui de novo é que nos regimes do que se costumou chamar de Terceiro Mundo, em que se inclui a maior parte dos países latino-americanos, existe uma discrepância bastante significativa entre racionalidade formal e racionalidade material. E isso significa que o problema já não é de direito mas de política. Dito de uma outra maneira, o problema com que se defrontam aquelas instituições é que ainda se está longe de superar a distância entre o modelo ideal de democracia que se quer e aquele que realmente existe. A pouca eficácia da atuação da OEA, como vêm demonstrando os casos peruano e haitiano, parece não levar em conta o diagnóstico que teria por base a seguinte pergunta: de que tipo de democracia estamos falando no caso da América Latina? Certamente essa pergunta aponta na direção de sugerir a existência de democracias (no plural) e não de democracia (no singular). Então a questão passa pela resposta à pergunta: qual é a democracia que se pratica nos países latino-americanos? 


\section{CONDICIONANTES POLÍTICOS DA ATUAÇÃO DA OEA}

A resposta a essa pergunta também passa pela constatação de que a exigência da aplicação da racionalidade formal aos sujeitos (chamem-se cidadãos ou estados) exige que, para atingir um certo grau de eficácia, a norma exige como condição a priori sua aplicação a sujeitos que agem e que existem em condições de igualdade. Como exigir racionalidade na escolha dos melhores governantes a um eleitor que não possui o mesmo nível ou acesso à informação quando comparado com um segundo que possui essas condições? O mesmo podemos dizer do exercício da democracia na América Latina. Como exigir a prática universal do modelo de democracia euro-americano nos países da região quando as condições geradas por fatores culturais (tradição autoritária), pelas profundas desigualdades sociais ou pelo baixo grau de institucionalização das chamadas regras do jogo impossibilitam um mínimo de congruência entre a racionalidade formal (exprimida juridicamente em constituições, cláusulas ou decretos) e a prática efetiva da democracia?

Numa rápida enumeração de suas características, o modelo de democracia representativa euroamericano caracteriza-se por uma alta institucionalização de suas práticas democráticas, o respeito pelo formação da vontade política por meio da regra da maioria, o funcionamento do mecanismo de accountability ou de prestação de contas (dos governantes para o demos ou dos principais poderes entre si), a incorporação dos grupos organizados e representativos de interesses sociais na definição e discussão da agenda política e a alta institucionalização dos mecanismos eleitorais que exprimem os desejos da maioria e da minoria na eleição de seus representantes. Esse tipo ideal, não é difícil concluir, está longe de ser o modelo de democracia prevalecente na América Latina. Seu contraponto é caracterizado na região pelo que Guillermo O'Donnell chamou de "democracia delegativa", que corresponde a um modelo mais realista de democracia: baixas definição e institucionalização das práticas democráticas e pouca transparência no exercício das regras do jogo eleitoral. Outro elemento notável desse arranjo democrático é o mito de que o Presidente, dado que foi eleito por uma maioria, pode fazer discricionariamente tudo, bastando para isso invocar e relembrar sempre qual foi o percentual de milhões de votos com que foi eleito. Também formam parte desse modelo real de democracia a ausência de um mecanismo ao mesmo tempo vertical e horizontal (entre os poderes públicos) de accountability e a definição unilateral da agenda pelo Presidente da República e seus principais assessores, sem levar em conta a voz de grupos de interesses e de outros segmentos públicos como partidos e o Parlamento. Acrescente-se a isso as constantes acusações trocadas entre Presidente e Congresso Nacional sobre o tema de a quem corresponde a responsabilidade pelas crises. $\mathrm{O}$ produto da soma desses elementos políticos é uma imensa solidão no poder por parte do Presidente da República, o que pode transformar-se em vazio de poder, resultando em perda de legitimidade do mandato popular algumas vezes ainda na metade do mandato. "Como institucionalizar uma democracia que faz diretamente o oposto daquilo que foi prometido?" (O'DONNELL, 1991).

A esses elementos teria que se adicionar um outro, evidenciado pela recente experiência peruana: o continuum de certas estruturas vigilantistas (caso dos corpos de segurança ou de inteligência estatal) do período autoritário, que, incrustadas no núcleo duro do Estado, usurpam a formação da vontade política de seus representantes. O paradoxo é que essas estruturas continuam agindo dentro do mesmo padrão autoritário e repressivo das ditaduras militares do passado, agora em condições políticas democráticas. Esse paradoxo evidencia o que O’Donnell chamou de segunda transição (aquele período que se inicia logo após o fim dos governos ditatoriais), que se tem prolongado e tem sido mais complexo e delicado do que podia prever-se. Indica também, novamente, a fragilidade ou a inexistência de accountability horizontal. A não-existência dessa condição da democracia moderna decorre de um insulamento sem controle do poder público, que se traduz na aparição de feudos de poder no interior do Estado que imprimem uma dinâmica autônoma (fora de todo controle) a suas ações.

É nessas condições internas descritas pelo tipo ideal de democracia delegativa que agem as organizações como a OEA nos processos eleitorais por meio de suas missões de observadores, ou MOE-OEA, como também são conhecidas. Para a atuação da OEA em relação a alguns de seus paísesmembros, essas condições internas de funcionamento da democracia real constituem um primeiro constrangimento ou limitação, ou, diríamos de outra forma, uma limitação estrutural, que não cabe ser 
superada por via da racionalidade formal. Inclusive a própria necessidade da existência de tal instrumento de observação dos processos eleitorais já indica, senão uma desconfiança $a$ priori da lisura dos processos eleitorais em alguns países da região, ao menos sugere, sim, que a eventualidade de "comportamentos impróprios" não pode ser descartada. Ante essa limitação de tipo estrutural, qual é a possibilidade de uma atuação eficaz das missões de observadores da OEA nos processos eleitorais? Isso depende de vários fatores. Depende, em primeiro lugar, de uma condição ad hoc: a vontade dos governantes e das elites locais em colaborar. A disposição para a colaboração, por sua vez, depende da maior ou menor sustentação popular das elites governantes. É oportuno lembrar que as democracias delegativas funcionam na base da afirmação de que o mandato outorgado pelo demos dá o direito de governar discricionariamente. Essa discricionariedade no exercício do poder vê-se reforçada pelo fato de que alguns desses governantes têm sido eficazes no combate a certos males (altas taxas de inflação, insegurança, terrorismo, narcotráfico etc.), razão por que, em uma reprodução do velho estilo paternalista da política latino-americana, os governados, ou uma parcela deles, sentem-se altamente gratos pelo "favor recebido". Isso explicaria que alguns governantes, como o paradigmático caso de Fujimori no Peru, ainda conservem boa aceitação popular a despeito de seus desaforos autoritários.

Da mesma maneira, essa disposição para colaborar pode basear-se em um cálculo das vantagens para as elites governantes. Aliás, isso nem sempre lhes significa desvantagens: a presença das missões de observadores pode transformar-se em um instrumento que transfere legitimidade ao processo em si, na medida em que suas avaliações positivas, a priori e a posteriori, podem servir como parâmetro de aceitação e referência para outros estados e organizações internacionais de natureza econômica e política. Porém, a disposição para a colaboração está muito condicionada pela correlação de forças internas à situação e às próprias forças opositoras: a intransigência de facções, de ambos os lados, polarizadas nas metáforas de "linhas dura" ou "branda", hard ou soft, "falcões" e "pombas", podem determinar tanto o rumo de uma eleição quanto a própria eficácia da presença dos observadores ${ }^{1}$.

1 No caso do segundo turno das eleições peruanas, um dos
Uma segunda limitação com que se defrontam as missões de observadores é de caráter sistêmico, isto é, o reconhecimento de que as agências estatais, governamentais, a oposição e as próprias missões de observadores (enquanto organizações internacionais) têm uma autonomia de atuação limitada pelas demandas e pressões do ambiente externo. "Em outras palavras, na noção de sistema não se contempla a possibilidade de que um dos atores atue sem que isso venha a provocar reações no entorno" (VILANOVA, 1995, p. 40). As reações à atuação de um ator podem ser de ordem local ou global. Tais deslocamentos, a favor ou contra a iniciativa do ator, manifestam-se em constrangimentos ou limitações à iniciativa dos quais um ator coletivo e multilateral como a OEA dificilmente escapa.

A isso se acrescenta uma terceira limitação rotineira referida à própria natureza de organização internacional como a OEA: a constituição predominantemente estatal da organização. Dada sua natureza, corresponde aos estados desempenhar o papel principal, o que traz a conseqüência quase óbvia de que no seu funcionamento esse tipo de organização apresenta a dupla característica de representante de interesses estatais e de organismo que procura agir com um mínimo de identidade própria. Porém, a evidente tensão que se gera em torno de ambas funções acaba resolvendo-se em favor da primeira. Não se deve esquecer que esse tipo de organização e atuação corresponde àquilo que Cox e Jacobson classificam na categoria de subsistemas representativos, "que são compostos pelas instâncias dos diferentes países, cujas interações (essencialmente nos próprios países) determinam a política perseguida pelos representantes de seus país no seio da organização em questão" (COX \& JACOBSON, 1990, p. 392). Atentando-se para a natureza estatal da OEA, chega-se a explicar-se, em parte, porque os esforços de democratização feitos por seus próprios subsistemas organizacionais (exemplificados por suas missões de observadores) acabam condicionados pela e limitados à definição dos interesses nacionais dos principais

fatores determinantes no fracasso da negociação entre o governo, a oposição e a missão de observadores da OEA foi a atitude intransigente adotada pela ala dos "falcões" do candidato Alejandro Toledo, que não aceitava uma data mínima de realização do segundo turno que não fosse o 18 de junho de 2000, quando a data que estava atingindo o consenso era o dia 11 de junho de 2000. 
estados que compõem a organização.

Essa hipótese pode ser compreendida de maneira mais ampla quando atentamos para um outro constrangimento que decorre do fato de ser a OEA constituída por países com dimensões de poder das mais variadas, dado que é composta de países com objetivos de política internacional marginais, de alcance médio e aqueles de objetivos estruturais. No primeiro caso estariam localizados a maior parte dos países integrantes da OEA. Um segundo grupo de países corresponde àquilo que Huntington chamaria de potências regionais principais (Brasil) e secundárias (Canadá, México e Argentina) (HUNTINGTON, 1999). Finalmente, a OEA apresenta na sua composição não só uma potência mas uma superpotência multidimensional. Evidentemente os conflitos mais sérios acabam dando-se entre a superpotência e a potência regional principal. Esses conflitos têm na sua origem o desejo de afirmação de autonomia local por parte da potência regional principal visando à afirmação de seu interesse nacional face região.

É inegável que esses conflitos frios têm sua repercussão na atuação de um organismo multilateral como a OEA. A origem desses conflitos relaciona-se ao desejo de liderança regional, nem sempre manifestado de maneira clara, porém sempre latente. E nesse ponto a questão deixa de ser diplomática para transformar-se em um problema de geopolítica: a afirmação da liderança da potência regional principal poderia resultar em um desequilíbrio do quadro clássico e histórico do mecanismo de balança de poder. Em relação a isso é necessário relembrar que o que se questiona no conceito de balança de poder não é sua procura por parte dos estados ou mesmo sua vigência histórica; o que se questiona em tal conceito, sobretudo a partir da Primeira Guerra Mundial, se é um dispositivo eficaz para atingir a paz no sistema internacional. E de alguma forma o sucessivo fracasso tanto da Liga das Nações como das Nações Unidas em implementar um mecanismo de segurança coletivo eficaz revigora esse instrumento como mecanismo para compreender-se a ação dos estados. Dessa maneira, a afirmação da liderança regional do Brasil na região é percebida tanto pela superpotência como pela potência regional secundária (Argentina) como um caso de desequilíbrio da balança regional de poder. Os pressupostos desse desequilíbrio estariam encarnados em temas como o processo de integração econômica regional, sob uma hipotética liderança brasileira, e também pela possibilidade de o mesmo Brasil passar a ocupar uma cadeira permanente no Conselho de Segurança da ONU. Nesse quadro, é tentador afirmar que uma forma de compensação do excedente de poder projetado do Brasil (isto é, potencial e não-real) passaria por um movimento no qual a potência regional secundária (Argentina) acompanhe, tanto por princípios quanto por pragmatismo, os deslocamentos ou contrafreios da superpotência em relação à potência regional principal. Certamente isso não significa que a potência regional secundária tenha sua política externa sempre atrelada à superpotência. Porém tambémé certo que nas últimas décadas (indiferente do governo ser de natureza militar ou democrática) houve pouca autonomia da política externa argentina em relação aos Estados Unidos. Colocadas assim as coisas, é possível pensar que a atuação argentina no caso das eleições peruanas, na qual acompanhou a posição dos Estados Unidos, reflita essa preocupação com a balança de poder. A questão aqui é: esse jogo regional de poder não acaba de maneira clara limitando a eficácia da atuação das missões de observadores? Ou, formulada a questão de outra maneira: a eficácia desse mecanismo não tem por limite o interesse nacional dos estados principais da organização?

\section{NÃO-INTERVENÇÃO E DEMOCRACIA NA AGENDA DA OEA}

Uma resposta melhor delimitada dessa questão leva-nos ao espinhoso tema da soberania em tempos de globalização. Um dos mitos popularizados na passagem de um século para outro é que os conceitos de globalização e de soberania são diametralmente antagônicos; a idéia subjacente a tal argumento é que o primeiro realiza-se em detrimento do segundo. Como afirmam Hirst e Thompson, o depositário da soberania (o Estado) ficaria assim relegado ao papel de gestor de assuntos relacionados à "política fria", tais como direitos humanos, direitos de minorias ou criação de serviços públicos necessários ao bom funcionamento dos agentes principais da globalização, os grandes conglomerados econômicos (HIRST \& THOMPSON, 1998). Sem dúvida os fluxos financeiros e as mudanças introduzidas pela era da informática e das telecomunicações ajudam a sustentar esse argumento. Ora, tal idéia deve ser considerada como uma premissa que é correta no que afirma, porém incorreta naquilo que nega. A globalização não significa necessariamente a diminuição da importância do conceito de soberania. E 
nem sempre aparecem como elementos antagônicos. Dois exemplos bastam para isso: 1) é possível constatar que quantitativamente o número de estados nos últimos anos tem aumentado: passou-se de 143 representados na Assembléia Geral da ONU em 1991 para quase 200 em 1999. Poder-se-ia argumentar que a maior parte desses estados, tanto antigos como aqueles que acabam de nascer como produto das implosões políticas, geográficas e étnicas do período pós-Guerra Fria, tem peso insignificante quanto a suas capacidades de poder no sistema internacional. Essa afirmação não é incorreta. Porém, como sustentado por Hobsbawm, por que os nacionais desses territórios não procuram agrupar-se sob novas formas de organização? Simplesmente porque continuam enxergando o Estado como o principal locus de identidade coletiva (HOBSBAWN et alii, 2000); 2) nem tudo o que é produzido pela globalização é oposto ao objetivo dos estados de afirmarem sua soberania: o desenvolvimento da informática e das telecomunicações permitiu ao Estado um maior controle técnico-burocrático sobre as atividades de seus cidadãos. Os modernos sistemas de arrecadação de impostos, utilizando-se dos mecanismos da internet, são um exemplo pertinente disso. Aliás, como vêm mostrando os positivos resultados da introdução do mecanismo de urnas informatizadas em eleições de países da região latino-americana, os desenvolvimentos materiais da globalização podem resultar em uma condição necessária, embora não suficiente, para assegurar padrões razoáveis de transparência eleitoral. Observadas as coisas a partir desses desdobramentos, podemos pensar em complementaridade e não em antagonismo entre globalização e soberania.

Ora, uma coisa é a globalização de fatores materiais (capital, tecnologia e mão-de-obra) e outra é a globalização dos valores e dos princípios (leiase dos princípios de democracia liberal). Nesse terreno tanto a globalização dos valores quanto a soberania medem força e, ao contrário do que poderia ser sustentado pelos globalistas, o resultado nem sempre é nefasto para o Estado, como demonstrou o exemplo das eleições peruanas. A assimetria entre universalização dos valores (assimilação dos princípios democrático-liberais), práticas reais e funcionamento efetivo das instituições democráticas acham seu maior empecilho no legado histórico do princípio de não-intervenção (talvez o maior legado da ordem estatista que se iniciou em Vestfália) que continua a ser invocado por qualquer Estado, independentemente do peso de suas capacidades de poder. E uma reflexão mais atenta sugere contradições latentes e reais entre a lógica estatal e a universalização ético-normativa da democracia liberal ocidental.

A maneira como os estados da região latinoamericana fazem uso do princípio de não-intervenção sugere duas estratégias. Uma primeira é de tipo normativa: trata-se de um princípio consagrado pela prática histórica iniciada em Vestfália, cuja observância possibilitou e contribuiu para dar uma relativa estabilidade, ou paz relativa, ao sistema internacional e aos subsistemas internacionais regionais. Além disso, em uma lembrança à introdução do Leviatã (HOBBES, 1997, p. 27), a alma do Estado é a soberania, e seu núcleo duro, na atuação frente a outras comunidades políticas, é o princípio de não-intervenção. Como resultante, temos, a partir dessa primeira perspectiva, uma colisão de dois princípios: o princípio democrático globalizado com o princípio de não-intervenção, intrínseco ao Estado nacional. Esse esclarecimento teórico é útil porque nesse conflito tende a confundir-se, às vezes, a invocação do princípio de nãointervenção como uma atitude realista ou pragmática por parte do Estado. Assim, a postura da diplomacia brasileira no seio da OEA, de não considerar as eleições peruanas no segundo turno como um processo ilegítimo, foi catalogada como um abandono, ou no mínimo um efeito suspensivo, dos princípios em favor de uma atitude que, visando ao interesse nacional, seria realista. $\mathrm{Na}$ verdade, tratou-se de uma escolha entre dois princípios, o que leva então a uma hierarquia de princípios, optando-se pelo princípio de não-intervenção. De um ponto de vista estritamente normativo, o critério que um Estado aplica para fazer essa escolha está ancorado no fato histórico da universalidade e da eficácia do princípio de não-intervenção como elemento gerador de estabilidade dos subsistemas internacionais. Aliás, a opção por esse princípio acha uma justificativa normativa no fato de ser acolhido pelo direito internacional da ONU.

Uma segunda estratégia é, agora sim, de caráter realista e já não de caráter principista: os cálculos sobre as conseqüências de uma atitude atrelada à retórica do princípio da universalidade democrática. Qual seria o ganho para a diplomacia brasileira ou para outros países da região (como a Venezuela) e para seus respectivos interesses nacionais, caso acompanhassem os pedidos de punição ao Peru, feitos pelos Estados Unidos, Canadá e Costa Rica? 
Na verdade, a conhecida saída diplomática brasileira, acompanhada por outros países da região como a Venezuela, o México e o Chile, de que era necessário guardar-se o devido "equilíbrio entre democracia e não-intervenção", exprimia uma instrumentalização do princípio de não-intervenção. Dito de outra maneira, o princípio serviu para solapar a procura (em perspectiva) de macro-interesses regionais, como no caso brasileiro, ou serviu como um guarda-chuva diplomático (o que também poderíamos chamar de "diplomacia preventiva"), como no caso da Venezuela, contra futuras intervenções veladas dos Estados Unidos. Nas novas condições, essas intervenções já não assumem, como no passado, a forma-base hard dos marines americanos e sim a forma soft dos princípios democráticos.

Essa reação de alguns países da região por via da instrumentalização do princípio de não-intervenção reveste-se de importância na medida em que é parâmetro para algumas constatações. A primeira tem a ver com o fato de que diferentemente dos dias da Guerra Fria, as posições dos Estados Unidos no seio da OEA já não atingem os consensos quase automáticos que antes atingiam. $\mathrm{O}$ contexto ideológico internacional agia como um mecanismo de pressão importante para atingir os pactos quase lockeanos de consentimento. Aqui voltamos a uma idéia já esboçada em páginas anteriores: já não se trata mais de punir países com inclinações por uma opção ideológica comunista mas de punir países que aceitam princípios de governabilidade internacionais idênticos mas com enormes dificuldades para colocá-los em prática. É claro que nisso também influi a tradição pragmática da potência regional primária da região, o Brasil. A partir dos anos trinta do século XX tem existido um continuum, raramente interrompido, no qual deixar de reconhecer ou de se relacionar diplomaticamente com países de regimes políticos autoritários ou de opções ideológicas diferentes da democracia liberal não tem sido um ponto de honra para a política externa brasileira.

Uma segunda constatação relaciona-se ao fato de os Estados Unidos não parecem ter percebido que nem todos os aspectos colocados na agenda da democracia global têm os mesmos efeitos e a mesma aceitação no sistema internacional. As reações são diferenciadas. Por exemplo, tomemos um tema dessa agenda: os direitos humanos. Poucos duvidam hoje em dia de que a universalização da democracia está ligada à universalização de direitos humanos que transcendam os particularis- mos e os parâmetros antropológicos do relativismo cultural. Isso forma parte de uma tendência dentro do sistema internacional que aceita com menos restrição a intervenção em alguns aspectos ou campos relacionados ao conceito de democracia global. Assim, ninguém duvida de que a intervenção militar feita no Cosovo em nome de direitos humanos genéricos, e não só específicos de uma etnia, tem mais possibilidades de ser aceita que a intervenção em um processo eleitoral, por mais ilegítimo que ele seja. Aliás, a redefinição da soberania estatal tendo por pano de fundo a questão dos direitos humanos é algo que já vem sendo constatado, desde os anos 1970, pela atuação humanitária de urgência de algumas organizações não-governamentais internacionais como os Médicos sem fronteiras e Medicina do mundo. Como sustenta Vilanova, comentando a atuação dessas organizações nãogovernamentais (ONGs): "O resultado final é sempre o mesmo: vem-se aceitando que o dever de ajuda humanitária leva diretamente ao direito de ingerência por motivos humanitários nos assuntos internos de um Estado. Isto é provavelmente uma das maiores conquistas da ação humanitária de urgência de nosso tempo" (VILANOVA, 1995, p. 97).

$\mathrm{O}$ item da agenda democrática globalista relacionado aos processos eleitorais é mais delicado. No caso da OEA, a dinâmica que justifica uma intervenção fica limitada à ruptura dos processos democráticos por meio da força. Não se pode esquecer que um dos argumentos utilizados por alguns países latino-americanos para o caso das eleições peruanas foi que medidas retaliatórias não se justificariam dado que não houve ruptura institucional, via uso da força. Falando de maneira realista, essa base de sustentação do argumento é bastante frágil. Na verdade, o argumento é novamente instrumentalizado. É uma forma solapada de alguns países da região fazerem um ajuste de contas em relação à atitude intervencionista estadunidense do passado, utilizando-se do guarda-chuva dos complexos e tortos caminhos do direito internacional. Dessa forma, os mecanismos da OEA para monitorar as eleições acabam reféns dos cálculos de interesses de seus membros e das interpretações jurídicas que se depreendem da legislação elaborada por ela mesma sobre a matéria.

De outro lado, nas atuais condições, a possibilidade de intervenção nos processos de democratização da região acabam tendo uma outra limitação na questão seguinte: como uma ação mais decidida e incisiva dos principais atores da OEA podem 
desestabilizar o posicionamento e a ação desses mesmos atores frente a outras questões relevantes e problemáticas na região? Tomando de novo por exemplo o caso peruano: seria conveniente para os Estados Unidos insistir no pedido de retaliação e na qualificação de legitimidade do processo eleitoral peruano quando o país mostra-se, e temse mostrado, estratégico para os planos de combate ao narcotráfico e ao terrorismo na região? Argumentando, novamente com base no realismo, bem feitas as contas, não seria preferível conviver com um aliado incômodo a deixar de contar com ele em futuras empreitadas, que podem compreender o combate à guerrilha, como no caso da Colômbia, ou neutralizar as ações de países com poucas simpatias na atualidade pelos Estados Unidos, como é o caso da Venezuela? Cabe muito bem aqui recordar a diferença entre a lógica de uma ação moralista e uma ação baseada na política. A respeito, Aron lembra que a política compreende por sua natureza a dualidade amigo-inimigo e que os Estados Unidos “[...] podem influenciar os países aliados no sentido desejável; mas não podem ir até o fundo da lógica do moralista [...]. Trata-se de uma questão de oportunidade, isto é, de prudência, e não de princípios, meter-se ou não nos negócios de outro país [...]. Nenhum 'monstro frio' obedece sempre aos direitos das gentes ou à moral" (ARON, 1987, p. 16-17).

Em outras palavras, a globalização dos princípios democráticos não estão isentos de escapar da lógica, muitas vezes inevitável, da Realpolitik. Como a Realpolitik ainda goza de boa aceitação na ação interestatal e como a natureza de organizações como a OEA é estatal, suas ações "moralizantes" dos processos democráticos na região evidentemente acham uma limitação considerável em sua eficácia nas relações de poder estabelecidas entre seus membros e nos desdobramentos que resultam das interações entre as peças principais do sistema internacional.

O reconhecimento da interação das partes do sistema internacional não se coloca em questão. Assim como também não se coloca em questão a premissa realista de que o principal problema para o funcionamento do sistema internacional é a ausência de um poder comum às partes. A isso Hoffman acrescenta mais um problema: "a ausência, ou pelo menos debilidade, de valores comuns subjacentes ao conjunto do sistema" (Hoffmann apud VILANOVA, 1995, p. 52). Certamente a presença do poder comum continua sendo uma grande meta do pensamento idealista, porém uma questão instigante é se a globalização da política, por via do modelo da democracia ocidental, não está começando a solucionar o problema colocado por Hoffman. Junto com o Estado, as organizações internacionais são os principais atores ordenadores do sistema internacional. Ora, corresponderia às organizações, antes que aos estados, o papel de socializador internacional dos valores da democracia ocidental. No entanto, a análise da atuação da OEA mostra que o sucesso desse papel não é tão fácil. Como veremos na seção seguinte, a própria indefinição dos limites da atuação das missões da OEA acaba dificultando mais ainda seu papel.

\section{MISSÕES DA OEA: ALÉM DE SUAS FUNÇÕES?}

Além dessas limitações estruturais, os países em que operam missões de observadores costumam responder aos questionamentos sobre a legitimidade de seus processos eleitorais alegando que esses mecanismos de inspeção e monitoramento extrapolam suas funções. Isso os transformaria em verdadeiros instrumentos de intervenção nos assuntos internos do Estado. É possível constatar isso no caso da OEA? São missões de observadores mesmo ou são instrumentos de intervenção nos assuntos internos dos estados? Uma resposta afirmativa a esse problema levar-nos-ia à conclusão de que tais instituições transformam a democracia num mecanismo de intervenção. De entrada estaria colocado o mérito da democracia no referente à sua superioridade moral frente a outras alternativas de governo. Aliás, do ponto de vista valorativo e da construção daquilo que hoje em dia se chama de cidadania global, seria difícil negar tal superioridade. Para aproximarmo-nos de uma resposta mais qualificada, examinemos mais atentamente $o$ mandato da Missão de Observadores da OEA no Peru.

Em cumprimento à Resolução n. 1753 da OEA, adotada em 5 de junho de 2000 pelos ministros de relações exteriores durante a Assembléia Geral da Organização em Windsor, Canadá, nomeou-se a chamada Missão Especial da Organização dos Estados Americanos para o Peru, que vinha a substituir a Missão de Observadores (MOE-OEA) que tentou monitorar, com pouco sucesso, o processo eleitoral peruano, chegando à conclusão de que "o processo eleitoral está longe de ser considerado livre e justo" (MOE-OEA, 2000, p. 1). Essa 
declaração oficial, evidentemente, não revela o fato de que se chegou a tal conclusão após intensas negociações entre governo, oposição, MOE e alguns diplomatas da região (principalmente do Brasil). Em documento da OEA de julho de 2000 pode-se ler que o mandato da Missão Especial é "propiciar o diálogo entre os diferentes setores da sociedade peruana e o governo, monitorar o processo de fortalecimento das instituições democráticas no Peru e a implementação das recomendações feitas pela Missão Especial durante sua visita a Lima de 28 a 29 de junho" (OEA, 2000, p. 1).

O ponto mais relevante dessa nota tem a ver com o que se entende por monitoramento e sobretudo com as recomendações ou propostas feitas pela Missão Especial da OEA. Com o nome de "elementos do processo", a Missão Especial recomendou um vasto processo de reformas institucionais nas quais se incluem "reforma da administração, fortalecimento do Estado de Direito e separação de poderes; liberdade de expressão e meios de comunicação; reforma eleitoral; fiscalização e balanço de poderes" (ibidem). Em outras palavras, recomenda-se um projeto de execução, stricto sensu, de uma reforma do Estado. É de praxe que nos estados nacionais sua reforma seja um processo encabeçado e dirigido por um poder constituinte originário (que exprime a vontade política popular por via de eleições). A pergunta que se depreende de tal recomendação é quase óbvia: a proposta de uma reforma de Estado não constitui uma ingerência nos seus assuntos internos? Não está uma missão atribuindo-se uma função que corresponde ao poder constituinte e que exatamente por tocar na alma do Estado (a ação do poder soberano), deve ser o resultado de um processo que expressa a vontade popular?

Não se discute a necessidade do monitoramento em democracias em que os processos de construção de instituições democráticas por via do sufrágio seja ainda muito pouco transparente. O problema parece consistir porém em que a prática do monitoramento transforma-se em uma prática de tutela dos processos das chamadas democracias delegativas. As atribuições da Missão Especial, que dá continuidade institucional à MOE-OEA, revela esse fato. Trata-se não de um simples monitoramento mas de influir na forma e no conteúdo que devem adquirir as instituições estatais. Aqui é relevante voltar a Aron: imiscuir-se nos assuntos internos de um Estado é uma questão de prudência, de oportunidade, e não simplesmente de vontade ou de posicionamento valorativo. Essa não é uma questão irrelevante para os estados, porque a saúde das democracias depende muito de que as instituições sejam construídas e reformadas de acordo com a vontade política nacional. No fundo ainda permanece aquela premissa estadunidense de julgar os processos de modernização política na América Latina à luz de sua própria experiência histórica, o que já tinha sido notado por Samuel Huntington nos anos 1960 no seu quase clássico livro $A$ ordem política em sociedades em mudança: "No confronto com os países em modernização os Estados Unidos levaram a desvantagem de sua história feliz. No seu desenvolvimento os Estados Unidos foram abençoados com abundância econômica, bem-estar social e estabilidade política. Essa agradável conjunção de bençãos levou os americanos a acreditar na unidade do bem, presumindo que todas as coisas boas vão juntas e que a consecução de um objetivo social desejável ajuda a consecução de outros" (HUNTINGTON, 1975, p. 18).

Uma proposta ousada de reforma do Estado como aquela feita pela OEA é extemporânea. Não no sentido de que o Estado peruano não precise reformar-se, porém no sentido conceitual, dado seu otimismo exagerado sobre o fim do Estado-nação. Supõe, de alguma forma, o enfraquecimento do Estado e a consolidação de estruturas de poder que se começam a colocar acima dos interesses dos estados. Entretanto, a militância democrática não pode desconhecer o fato de que uma grande variedade de estados nacionais ainda são suficientemente fortes para estabelecer seus objetivos políticos de longo prazo, em que não se ignoram a influência e as pressões do ambiente externo. Voltando a uma idéia com a qual trabalhei em outro lugar, o que é certo é que o Estado continua sendo o principal ator das relações internacionais. Porém isso não significa que, como no período da Guerra Fria, continue mantendo exclusividade como ator e como único centro de decisão.

Uma outra questão é que o próprio fato de certas propostas serem apresentadas com um viés intervencionista já comprometem a eficácia dos organismos de observadores e de monitoramento. Acaba restando-lhes eficácia a suas ações porque isso supõe a polarização de resistências e apoios dos atores envolvidos. Porém o resultado costuma ser o desgaste político da iniciativa. Novamente não devemos esquecer que esse é o resultado, 
previsível, da OEA ser uma organização de natureza estatal, para quem convergem interesses diversos. Isso fica evidente quando se contrasta o papel de uma organização interestatal como a OEA com uma organização não-governamental encarregada também de monitorar processos eleitorais. Por exemplo, a atuação de uma organização não-governamental internacional, de origem americana e adotando o mesmo discurso da globalização democrática, como é o Centro Carter (dirigido pelo exPresidente americano Jimmy Carter) registra menos resistências e menos polêmicas quanto a seus métodos de monitoramento e formas de atuação nos processos eleitorais dos quais participa em caráter de observador internacional. O ex-Presidente americano define da seguinte maneira o que seria o papel de um observador internacional: "confirmar o fato de que o partido no governo está realizando eleições honestas e garantir aos partidos de oposição que em caso de fraude, esta será denunciada. Também fazer saber aos votantes que, embora tenham dúvidas sobre o processo, existem observadores independentes para garantir que a eleição seja honesta e transparente. E servir de fiador de que a eleição foi correta" (El Nacional, 2000).

Da forma de atuação dessa organização nãogovernamental podem se derivar dois questionamentos importantes para a atuação dos organismos de monitoramento de natureza interestatal como a OEA. Primeiro, qual é o grau de institucionalização de seus procedimentos de monitoramento, isto é, qual é o grau de legalidade, regularidade, regulamentação e estrutura material para a atuação do organismo de monitoramento? E segundo: qual é o limite de sua atuação e de seus objetivos? Atente-se para o fato de que, em contraste com uma organização não-governamental como a Carter (em que os objetivos de sua missão de observador são mais claramente definidos), no caso das missões de observadores da OEA seus mecanismos de atuação são nebulosos. Examinando-se uma boa parte da documentação produzida pela MOE-OEA para o Peru entre maio e junho de 2000, não fica claro quais seriam os limites de sua atuação no caso do processo eleitoral desse país. Assim não é difícil que o resultado de sua atuação acabe misturando boa-fé no monitoramento com iniciativas que, sem necessariamente serem intencionais, acabam colidindo com funções que cabem só a um país definir. Isso resulta em que as vozes que pedem a regulamentação dos observadores internacionais em processos eleitorais nacionais se façam escutar com mais freqüência ${ }^{2}$.

De outro lado, mesmo que raciocinemos de um ponto de vista realista, segundo o qual em uma organização, uma vez traçados certos objetivos, é necessária a existência de uma estrutura ou regras de procedimentos punitivos, caberia perguntar: qual é a eficácia da estrutura punitiva da OEA em relação a países que agem fraudulentamente em processos eleitorais? Aliás, o caráter punitivo das organizações internacionais é uma tendência que se vem desenhando hoje com muita força no cenário internacional, como foi indicado nas páginas iniciais deste trabalho. Essa estrutura punitiva não é própria só de organizações de natureza militar como a OTAN, como também de algumas organizações internacionais de natureza econômica e financeira como a Organização Mundial do Comércio e o Fundo Monetário Internacional.

A presença dos Estados Unidos na organização poderia ser tomada como uma condição suficiente para a eficácia de certas medidas punitivas em relação a esses países (exemplo dos embargos econômicos)? De novo nos encontramos aqui com a limitação histórica derivada da mudança de época, o que não deixa de ser um paradoxo para os Estados Unidos: se a queda do bloco socialista hegemonizado pela União Soviética significa a vitória do liberalismo político e econômico e também, de outro lado, afastado o espectro fantasmagórico do comunismo, o apoio às iniciativas americanas, sejam diplomáticas, militares ou econômicas, transformase em um processo mais complexo na barganha diplomática internacional, mesmo tratando-se de países pertencentes tradicionalmente à chamada esfera de influência ocidental. Adicionalmente, as potências regionais principais da mesma esfera (caso do Brasil) passaram não só a ter mais poder de barganha como ganharam mais autonomia nas suas iniciativas. A moral da história consiste em que os tempos em que uma simples pressão estadunidense no seio da Organização sobre os países da região era suficiente para angariar apoio a suas iniciativas punitivas (talvez com a notável exceção do México) já não se repetem com facilidade.

Também não se pode esquecer que, de uma forma ou de outra, a existência de regimes que estão

2 O governo venezuelano, por meio de sua chancelaria, manifestou esse desejo nas mega-eleições realizadas em julho de 2000 . 
perto de ter características daquilo que segundo Phillipe Schmitter, são subprodutos do apoio encoberto ou da própria omissão da potência americana e de alguns países da região. Assim, a implementação de medidas punitivas efetivas tem como limitação a possibilidade de negociar uma saída honrosa para antigos aliados que hoje são incômodos ${ }^{3}$. A experiência de Somoza na Nicarágua de finais de 1970 (abandonado pelos Estados Unidos, quando o triunfo sandinista fez-se inevitável) e o processo traumático que se seguiu à sua queda devem ter mostrado não só aos Estados Unidos como também aos principais países latinoamericanos os limites do que Aron chamou de ação moralista.

Finalmente, procede também uma limitação de ordem conceitual que diminui a possibilidade da eficácia punitiva. Essa limitação está relacionada com a crença de que a modernização política dos países da região latino-americana tem como base sua modernização econômica. Essa modernização foi pensada no passado a partir de programas como a chamada Aliança para o Progresso, nos anos 1960, e hoje a partir das fórmulas liberais aplicadas, com maior ou menor sucesso, em uma boa parte da região desde a segunda metade dos 1980. Mesmo que se tratasse de uma ruptura institucional por um golpe militar ou civil, pouca dúvida resta de que a opção de punir um país por meio do uso coordenado da força é uma opção que no seio da OEA teria pouco apoio político. A opção punitiva mais viável poderia ser uma ruptura de relações diplomáticas (pouco provável também) ou uma punição econômica ao estilo de um embargo à cubana. Novamente, sem contar que são outros os tempos, uma punição dessa natureza seria uma contradição com o princípio conceitual esboçado acima que procura a modernização política na modernização econômica. O remédio pode mostrarse mais forte que a doença. A coerência de raciocínio indicaria que medidas punitivas de tipo econômico poderiam ter um efeito regressivo na construção institucional democrática.

\footnotetext{
3 Dessa maneira, a atitude aparentemente dura dos Estados Unidos ao desqualificar como ilegítimo o processo eleitoral peruano não passava de um balão de ensaio que procurava testar as reações dos países da região e mesmo a reação do governo peruano.
}

\section{CONSIDERAÇÕES FINAIS}

Não se pode desconhecer que, no mundo pósGuerra Fria, as organizações internacionais surgem, ao lado dos estados, como os principais atores que informam e organizam as relações internacionais. Aliás, algumas dessas organizações começam a ter um papel efetivo como fonte de legitimidade dos atos estatais em alguns cenários internacionais. $\mathrm{Ou}$ seja, seu consentimento para a ação estatal é condição importante (embora não suficiente) tanto da legalidade de um ato quanto de uma aceitação maior desse mesmo ato por parte da opinião pública mundial. Contudo, nas organizações multilaterais que tratam de temas de natureza diplomática ou de segurança (casos da ONU e da OEA) os atores estatais médios e menores (em termos de capacidades de poder) que delas participam ganharam maior autonomia frente aos estados hegemônicos. De alguma forma opera-se uma tendência que já havia sido apontada por Celso Lafer e por outros autores como o próprio Hobsbawm: no sistema internacional contemporâneo coexiste uma tendência à globalização da diplomacia com uma tendência à fragmentação. Ou bem como reflexo do mundo dos estados ou bem como atores autônomos, as organizações internacionais tendem a refletir ambas as tendências. Porém, ambas refletem-se no interior das organizações de uma forma bastante tensa na medida em que o elemento de consenso e de coesão (o aspecto ideológico) já não existe mais. Dessa maneira, a globalização é procurada pelos atores hegemônicos em termos de valores universais vitoriosos enquanto os que caminham pelo lado da fragmentação apelam para o princípio da realidade (leia-se: os estados ainda são soberanos e a nação ainda existe).

Nessas organizações de natureza diplomática e de segurança, o grande paradoxo parece consistir no seguinte: na medida em que a política (em termos de valores) tende a generalizar-se como idéia dominante, opera-se uma fragmentação do consenso sobre os limites dessa idéia. Ante a idéia do inimigo comum (o comunismo) nada havia a objetar. Porém, na sua ausência, os consensos tornaram-se mais raros.

Essas referências conceituais são de fácil constatação numa organização como a OEA e em seus instrumentos operacionais chamados de missões de observadores ou missões especiais, encarregados de monitorar processos eleitorais no que se chamou ao longo deste artigo de democracias 
delegativas. Ela também convive com tendências conflitivas entre a globalização e a fragmentação, ou entre a universalização da política e sua regionalização. Nesses cenários parece sobrar muita vontade política de alguns atores no interior da OEA, que acabam iludindo-se um pouco sobre as conseqüências práticas ou reais de suas ações. A democracia liberal, sobretudo no seu ideário e legado político, é amplamente desejável e é, quiçá, o único regime em que se é possível aspirar a um conceito pleno de cidadania. Entretanto, não é possível tentar elevar a realização de eleições "livres e justas" (valendo-nos do jargão da OEA) a um fim em si mesmo no contexto do funcionamento das democracias delegativas. Esse é outro velho mito normativo dos formuladores da política externa americana em relação à América Latina. Tal idéia também já havia sido apontada corretamente por Huntington na sua citada obra $A$ ordem políticas nas sociedades em mudança: "a sua fórmula geral é que os governos devem basear-se em eleições livres e honestas. Em muitas sociedades em modernização, essa fórmula não tem nenhum valor. Para terem sentido, as eleições pressupõem um certo nível de organização política. O problema não é realizar eleições mas criar organizações" (HUNTINGTON, 1975, p. 19).

Na criação de instituições, como pré-requisito para a democracia, tem-se avançado bastante nas últimas décadas. O problema parece consistir também em que não basta a simples criação de instituições quando não se leva em conta que seu processo de modernização política tem sido incompleto, devido a seu baixo grau de institucionalização, reflexo do atrelamento à versão patrimonialista histórica por oposição a uma visão racionalista. Esse determinante estrutural determina inclusive o próprio comportamento das organizações que nascem na sociedade civil. Muitas delas passam a dar continuidade à tradição patrimonialista no relacionamento com seus representados e no seu relacionamento com o poder público. $\mathrm{O}$ déficit de institucionalização é decorrente também do fato de que na maioria de nossos países não houve um processo paralelo de construção de Estado e da sociedade civil mas a consolidação precoce do Estado. Ao contrário do que pensa Huntington, o déficit institucional não foi de Estado mas de sociedade civil.

As considerações destacadas neste artigo podem ser elencadas como hipóteses parciais para explicar o insucesso de práticas institucionais que formam parte das regras do jogo da democracia liberal em países de modernização política incompleta. Essas propostas explicam, em parte, porque as eleições em alguns países da região latino-americana, mesmo com seus inegáveis avanços, ainda não são um padrão institucional no qual a transparência caracterize de maneira permanente seus resultados. Entretanto, a incompreensão e a elevação das eleições a dogmas democratizantes parecem estar estimulando um comportamento das organizações internacionais de observadores no qual os limites entre voluntarismo e intervencionismo não aparecem suficientemente definidos. A questão que fica para a reflexão é: qual é o limite dessa espécie de cruzada civilizatória feita em nome da universalização dos valores democráticos? Qual é sua eficácia na construção de padrões institucionais democráticos, pensados em termos de práticas e de organizações?

Rafael Duarte Villa (rafaelvi@usp.br) é Doutor em Ciência Política pela Universidade de São Paulo (USP) e professor do Departamento de Ciência Política da USP.

\section{REFERÊNCIASBIBLIOGRÁFICAS}

ARON, R. 1987. Os últimos anos do século. Rio de Janeiro : Guanabara.

BOBBIO, N. 1984. O futuro da democracia : uma defesa das regras do jogo. Rio de Janeiro: Paz e Terra.

COX, R. W. \& JACOBSON, H. K. 1990. Uma primeira abordagem : a análise da tomada de decisão. In: BRAILLARD, P. (org.). Teoria das relações internacionais. Lisboa : Fundação Calouste Gulbenkian.

GUIMARÃES, S. P. 1999. Quinhentos anos de periferia. Porto Alegre: UFRS.

FUKUYAMA, F. 1999. No décimo aniversário de "O fim da história?” Política Externa, São Paulo, 
v. 8, n. 2, p. 61-86, set.-nov.

HIRST, P. \& THOMPSON, G. 1998. Globalização em questão. $2^{\mathrm{a}}$ ed. Petrópolis : Vozes.

HOBBES, T. 1997. Leviatã, ou matéria, forma e poder de um Estado eclesiástico e civil. Col. "Os pensadores". São Paulo : Nova Cultural.

HOBSBAWN, E., FUKUYAMA, F., ASH, T. G., ASNER, P. \& LUTTWARK, E. 2000. Depois do primeiro ato. Debate. Folha de S. Paulo, 07.maio, caderno Mais!, p. 04-11.

HUNTINGTON, S. 1975. A ordem política em sociedades em mudança. São Paulo: Forense

Universitária-USP.

1999. A superpotência solitária. Gazeta Mercantil, S. Paulo, 12.mar., caderno Foreign Affairs, p. 23-28.

KISSINGER, H. 1999. Diplomacia. $2^{\text {a }}$ ed. Rio de Janeiro : Francisco Alves.

O'DONNELL, G. 1991. Democracia delegativa? Novos Estudos CEBRAP, São Paulo, n. 31, p. 25-40, out.

SCHMIDT, C. 1992. O conceito do político. Petrópolis : Vozes.

VILANOVA, P. 1995. El estado y el sistema internacional. Barcelona : UEB.

\section{OUTRASFONTES}

El Nacional. 2000. Caracas, 31.jul.

MOE-OEA. 2000. Boletim n. 12, de 25 de maio. Lima : Missão de Observadores-Organização dos Estados Americanos.
OEA. 2000. Misión especial de la OEA que preside el ministro Eduardo la Torre viajará hoy a Lima. Documentos da OEA, Lima, 17.jul. 